\title{
Healthcare employees' work-related victimization and use of preventive measures
}

\author{
Gordon L. Gillespie ${ }^{1}$, Bonnie S. Fisher ${ }^{2}$ \\ 1. College of Nursing, University of Cincinnati, Cincinnati, OH, United States. 2. School of Criminal Justice, University of \\ Cincinnati, $\mathrm{OH}$, United States.
}

Correspondence: Gordon Lee Gillespie. Address: College of Nursing, University of Cincinnati, P.O. Box 210038, Cincinnati, OH, United States. E-mail: gordon.gillespie@uc.edu

Received: J une 19, 2014

DOI : $10.5430 /$ jha.v3n5p170

Online Published: July 15, 2014

Accepted: July 4, 2014

URL: http://dx.doi.org/10.5430/jha.v3n5p170

\section{Abstract}

Work-related victimization affects 14.6 per 10,000 employees in the United States annually. Little is known about work-related victimization in healthcare or the preventive measures taken by employees and employers. A secondary analysis was conducted of the Workplace Risk Supplement (WRS) data from 4,213 healthcare employees. Mental health field employees reported a significantly higher percentage of being victimized while at work, worrying about victimization, having knowledge of rules or guidelines addressing workplace violence, and receiving education/ information on workplace violence compared to medical field respondents. Implications for hospital administrators based on study results are presented.

\section{Key words}

Violence, Workplace, Crime victims, Health personnel

\section{Introduction}

No occupation is immune from work-related victimization; thousands of employees annually in all major occupational groups are victimized while at work ${ }^{[1,2]}$. Work-related victimization, or workplace violence, includes acts of abusive language or threats, threat with a weapon, physical assault, sexual harassment, attempted rape, and rape against healthcare employees instigated by patients, visitors, and coworkers ${ }^{[3]}$. Work-related victimization is a well-documented problem for healthcare employees occurring more frequently than in private industry ${ }^{[4]}$. In fact, the Bureau of Labor Statistics reports that the incidence rate of work-related victimization against healthcare employees is 14.6 per 10,000 full-time employees compared to 3.8 per 10,000 full-time employees in all private industry ${ }^{[4]}$.

While the problem of work-related victimization in healthcare is known to hospital administrators and risk managers, little is known about the victimization between major fields within healthcare or the protective measures taken by employees and employers to prevent victimization while at work. It is important to understand differences between major fields within healthcare so that hospital administrators and risk managers can focus limited resources towards the field with the greatest burden of work-related victimization and implement protective measures to prevent the victimization of healthcare employees while at work. Therefore, the focus of this article is to help inform hospital administrators about the 
types of risk for work-related victimization between medical and mental health fields and identify measures used by their employees to protect against victimization while at work.

\subsection{Work-related victimization}

Researchers routinely report the incidence of work-related victimization against healthcare employees for single occupations such as nurses or physicians; however, research with a general U.S. healthcare sample is lacking. Only two published studies present findings about work-related victimization for healthcare in general ${ }^{[5,6]}$. Jenkins et al. (2012) analyzed data from the 2002 Workplace Risk Supplement (WRS) of the National Crime Victimization Survey (NCVS) finding that approximately $4 \%$ of the 55,158 survey respondents experienced work-related victimization. Further, they reported that $25.5 \%$ of healthcare employees reported work-related victimization which represented a six-fold larger burden of work-related victimization in healthcare compared to the general working population. Kitaneh and Hamdan discovered a similar concern: nearly a fifth of Palestinian healthcare employees will experience work-related victimization each year ${ }^{[6]}$. Although both studies are informative, neither reported detailed findings for work-related victimization for United States' healthcare employees nor two major fields within healthcare: the medical field and the mental health field. The medical field includes medical and surgical physicians, nurses, allied health professionals, and unlicensed assistive personnel working in clinical and ancillary departments. The mental health field includes psychologists, social workers, and unlicensed assistive personnel working in clinical and ancillary support positions.

An even higher percentage of medical field and mental health field employees have reported a lack of perceived safety compared to the percentage of employees reporting work-related victimization. In a cross-sectional study of a national sample of emergency nurses working in the United States, 67\% $(\mathrm{n}=2,322)$ did not feel safe from being victimized while at work ${ }^{[7]}$. In addition, the emergency nurse participants in a quasi-experimental study of six Midwest United States' emergency departments felt significantly $(p=.004)$ less safe than physicians about the potential for future violence while at work ${ }^{[8]}$. A convenience sample of nurses $(n=302,86.4 \%)$ working in remote areas of Australia were concerned for their personal safety in relationship to work-related victimization ${ }^{[9]}$. Approximately $14 \%$ of a convenience sample of social workers working in the United Kingdom felt extremely vulnerable or very vulnerable to work-related victimization ${ }^{[10]}$; whereas, Hegney, Tuckett, Parker, and Eley found that $57 \%$ of victimized Australian nurses from a stratified random sample did not consider their workplace adequately safe ${ }^{[11]}$. No published studies to date have offered a broad view or comparison of healthcare fields for perception of safety from work-related victimization.

Healthcare employees perceiving their work environments to be unsafe may have led them to worry about or fear work-related victimization. Worrying about victimization was a problem in Taiwanese, Irish, and Canadian healthcare settings and worrying increased after being victimized ${ }^{[12-14]}$. In a survey of pharmacy managers and owners in Ireland, $39 \%(n=42)$ reported that their employees feared work-related victimization and $63 \%(n=68)$ worried about future violent incidents ${ }^{[13]}$. Fear of being victimized also was identified with previously assaulted physicians and nurses working in Palestinian hospitals and social workers and nurses providing care in isolated Canadian communities (Hutchings et al., $2011)^{[6,14]}$. A limitation in worrying about and fear of work-related victimization research is the lack of studies focusing on United States' respondents working in medical or mental health fields.

\subsection{Organizational and personal protective measures}

Hospital administrators have implemented a variety of organizational protective measures to prevent and mitigate work-related victimization including controlling access to patient treatment areas and employing security officers. Blando et al., Casteel et al., and McPhaul et al. found variation in healthcare facilities' ability to control access by locking doors, having visitors check-in upon arrival, and separating employee work stations from patient treatment areas reflecting an impracticality to rely exclusively on this as a protective measure ${ }^{[15-17]}$. Another measure for violence prevention is the use of security officers. Emergency department employees, however, have mixed perceptions related to the effectiveness of security officers to prevent or intervene during work-related victimization ${ }^{[18]}$. 
Employees also may use personal protective measures to promote their individual safety while at work. Examples of personal protective measures that healthcare employees can use are blowing an emergency whistle, activating a portable panic alarm, and pushing a stationary panic alarm ${ }^{[15]}$. While protective measures are essential to the protection of healthcare employees, the availability and use of organizational and personal protective measures are not known in a large sample of healthcare employees working in the United States.

\subsection{Summary of the background}

In summary, work-related victimization is a well-known problem in healthcare; however, researchers have not previously described the problem of work-related victimization with a representative sample of healthcare employees in the United States. This current study not only fills this gap in the work-related victimization research, but also expands the understanding of this body of research by (1) comparing the rates of work-related victimization between medical and mental health field employees, (2) reporting the organizational and personal protective measures in place to protect healthcare employees from work-related victimization, and (3) further exploring the findings of the WRS reported by Jenkins et al. from which little information has been reported ${ }^{[5]}$. These findings will be beneficial to hospital administrators and risk managers as they make financial resource decisions related to policy and practice changes for the safety of healthcare employees and prevention of work-related victimization.

\section{Methods}

A secondary analysis using de-identified WRS data from the 2002 NCVS was conducted. Trained interviewers employed by the U.S. Census Bureau administered the WRS using computer-aided telephone interviews from January to June 2002. A total of 47,694 individuals living in the U.S. at least 16 years old and employed during the week prior to the interview and for at least two consecutive weeks at any time during the six months prior to the interview completed the WRS. The respondents were identified using a stratified, multistage cluster design. Of the respondents, 4,213 met the inclusion criteria for this study of working in healthcare in the medical field or mental health field. Additional details about the methodology are available from the Inter-university Consortium for Political and Social Research and Jenkins et al ${ }^{[5,19]}$.

\subsection{I nstrumentation}

The NCVS was deployed in 1973 for use by the Bureau of Justice Statistics to obtain details about victims and consequences of crime, numbers and types of crime, and longitudinal measures of crime ${ }^{[19]}$. The NCVS includes questions about age, sex, educational attainment, race, employment, and victimization.

The WRS is a 25 -item supplement modeled after the Victim Risk Supplement of the NCVS ${ }^{[5,20]}$. The WRS was administered after respondents had completed the NCVS. Questions on the WRS relate to employment history, work shift, traveling for work, perceived safety of the work environment, worry about victimization, and protective measures used by employers and respondents.

\subsection{Outcome measures}

The key outcomes are work-related victimization, worry about work-related victimization, personal protective measures, and organizational protective measures. Work-related victimization was operationalized by respondents answering "Yes" to a series of questions for different types of work-related victimization such as being hit, threatened, or raped. Worry about victimization was operationalized by respondents answering "Yes" to the question: "(Do/Did) you worry that someone at your workplace might attack you or threaten you with harm?" Respondents who said "Yes" were further asked to state their relationship with the potential offender; responses included customer/client/patient, supervisor/employee/ coworker, or someone else. Personal protective measures were operationalized by respondents indicating that they carried mace or pepper spray, a personal alarm, or a weapon to prevent work-related victimization. Organizational protective measures was subcategorized as security measures in the workplace, written rules or guidelines about workplace 
violence, and education/information on work-related victimization. Security measures was operationalized by respondents answering "Yes" to the presence of one or more types of security measures present in the workplace used to prevent access to the workplace, prevent or mitigate workplace violence, and prevent weapons from entering the workplace. Written rules or guidelines were operationalized by participants stating "Yes" to the question: "(Does/Did) your employer have a written set of rules or guidelines regarding workplace violence?" Education/information was operationalized by respondents reporting the receipt of written materials or training on workplace violence while working for their employers.

\subsection{Occupation measure}

The NVCS respondents were asked to identify the occupation that best described their work. Eighty-six percent $(\mathrm{n}=$ $47,638)$ of the respondents answered this closed-ended question. Approximately $13.7 \%$ percent $(n=7,539)$ of respondents answered "Something else" for their occupation and provided a verbal description of their job. The second author recoded occupation responses to align with the BLS Standard Occupational Classification system ${ }^{[2]}$. The occupation for 59 respondents remained uncoded. The first author reviewed the qualitative employment descriptor for these respondents and classified 51 descriptors to a specific healthcare occupation. The sample of 47,638 was then reduced to only those respondents with a healthcare occupation resulting in an analytical sample size of 4,213 respondents who reported working in the medical field $(\mathrm{n}=3,696)$ or mental health field $(\mathrm{n}=517)$.

\subsection{Demographic measures}

Respondents were grouped based on birth year to allow for a generational comparison: Traditionalists (born 1925-1945), Baby Boomers (born 1946-1964), Generation X (1965-1981), and Millenials (born 1982 or later). Respondents' race was coded: White, Black, and other persons of color. The code "other persons of color" included small group sizes for respondents who were Asian/Pacific Islanders and American Indian/Aleut. Years with current employer were categorized based on Benner's novice to expert categories: less than one year (novice), one year (advanced beginner), 2-3 years (competent), four years (proficient), and five or more years (expert) ${ }^{[21]}$.

\subsection{Hypotheses}

The incidence of workplace violence is not uniformly distributed across healthcare occupations. Past research has reported differences between selected groups (e.g., emergency and psychiatric department employees) in the rates of workplace violence. Casteel et al. found a higher rate of victimization for employees working in California psychiatric units (2.31 per 100,000 employee hours per year) compared to employees working in California emergency departments ( 0.60 per 100,000 employee hours per year) ${ }^{[16]}$. Shiao, Tseng, Hsieh, Hou, Cheng, and Guo reported that the annual incidence of victimization while at work was significantly $(p<.0001)$ higher for Taiwanese nurses working in psychiatric settings (182.9 per 100 full time equivalencies [FTE]) compared to medical settings ( 37.9 per $100 \mathrm{FTE})^{[22]}$. These findings suggest that victimization against mental health employees would likely be higher in comparison to medical field employees. However, neither sample was drawn from a large U.S. representative sample. Patients deemed most likely to enact violence against healthcare employees are those with a mental health disease or disorder ${ }^{[7,23]}$. Given that all patients receiving care by mental health field employees have a mental health disease or disorder and mental health nurses are more likely to be victimized while at work, mental health field employees may be more worried about being victimized while at work compared to medical field employees. Guided by this past research, two hypotheses were developed:

Hypothesis 1: A larger percentage of mental health field employees will report work-related victimization compared to medical field employees.

Hypothesis 2: A larger percentage of mental health field employees will worry about being attacked or threatened at work compared to medical field employees. 
Past research also supported the development of four hypotheses related to the use of organizational and personal protective measures. Peek-Asa et al. (2009) found that of psychiatric departments in California and New Jersey, 94\% had security measures in place, $92 \%$ had policies and procedures addressing workplace violence, and $95 \%$ provided workplace violence training to their employees ${ }^{[24]}$. Similar findings for medical healthcare settings were not found indicating that organizational protective measures may be in place more frequently for mental health settings compared to medical healthcare settings. Blando et al. reported that the use of personal alarms were only used by medical employees in $4 \%$ $(n=2)$ of New Jersey emergency departments ${ }^{[15]}$. With work-related victimization occurring more often in psychiatric settings, it is likely that the use of personal protective measures such as personal alarms would be larger by mental health field employees compared to medical field employees. These research findings led to these additional hypotheses:

Hypothesis 3: A larger percentage of mental health field employees will have security measures present in the workplace compared to medical field employees.

Hypothesis 4: A larger percentage of mental health field employees will report having written rules or guidelines addressing workplace violence compared to medical field employees.

Hypothesis 5: A larger percentage of mental health field employees will receive education/information on workplace violence compared to medical field employees.

Hypothesis 6: A larger percentage of mental health field employees will use some type of self-protection compared to medical field employees.

The results from testing these six hypotheses can be used to inform the practice of hospital administrators. Hospital administrators may use these findings to justify allocation of resources to practice areas with a greater need as well as identify additional strategies to protect employees from victimization. In addition, study findings can be used as a benchmark to compare work-related victimization, personal protective measures, and organizational protective measures to contemporary practices.

\subsection{Data analysis}

Cross tabulations of the outcome measures by medical field and mental health field employees were generated to calculate frequencies and percentages. The relationship between categorical demographic and outcome measures by medical field and mental health field were assessed using Chi-square tests. Participants' age was compared by type of field using an independent samples $t$-test. Analyses were conducted using IBM SPSS Statistics 21 (IBM Corp., Armonk, NY). Alpha was set at 0.05 .

\section{Results}

There were 517 (12.3\%) respondents working in the mental health field and 3,696 (87.7\%) respondents working in the medical field. The sample was predominantly female $(\mathrm{n}=3,320 ; 78.8 \%)$, white $(\mathrm{n}=3,464 ; 82.2 \%)$, Baby Boomers $(\mathrm{n}=$ $2,161 ; 51.3 \%)$, and with the same employer for at least five years $(\mathrm{n}=2,042 ; 48.5 \%)$. Significant distributional differences were found between mental health field and medical field respondents based on sex $(p<.001)$, race $(p<.001)$, and generational age group $(p=.036$; see Table 1$)$. The mean age for mental health field respondents was 42.8 years $(S D=$ 12.7, range 17-76 years) and for medical field respondents was 41.7 years $(S D=11.9$, range 16-80 years). The mean age for mental health field respondents was significantly higher than medical field respondents $(t[647.2]=2.003, p=.046)$. No significant distributional differences were found between the mental health field and medical field respondents for tenure with current employer $(p=.336)$ or primary work shift $(p=.823)$. 
Table 1. Demographic and employment characteristics $(\mathrm{N}=4213)$ \#

\begin{tabular}{|c|c|c|c|}
\hline & Mental health field & Medical field & $X^{2}$ (p-value) \\
\hline Female & $359(69.4 \%)$ & $2961(80.1 \%)$ & $30.940(p<.001)$ \\
\hline \multicolumn{4}{|l|}{ Race } \\
\hline White & $418(80.9 \%)$ & $3046(82.4 \%)$ & \multirow{3}{*}{$16.142(p<.001)$} \\
\hline Black & $89(17.2 \%)$ & $468(12.7 \%)$ & \\
\hline Other & $10(1.9 \%)$ & $182(4.9 \%)$ & \\
\hline Hispanic ${ }^{*}$ & $45(8.8 \%)$ & $291(7.9 \%)$ & $0.428(p=.513)$ \\
\hline \multicolumn{3}{|l|}{ Generational age groups (age in years) } & \multirow{5}{*}{$8.548(p=.036)$} \\
\hline Millennials (16-20) & $8(1.5 \%)$ & $94(2.5 \%)$ & \\
\hline Generation X'ers (21-37) & $175(33.8 \%)$ & $1301(35.2 \%)$ & \\
\hline Baby Boomers (38-56) & $258(49.9 \%)$ & $1903(51.5 \%)$ & \\
\hline Traditionalists $(57+)$ & $76(14.7 \%)$ & $398(10.8 \%)$ & \\
\hline \multicolumn{3}{|l|}{ Tenure with current employer (years) } & \multirow{6}{*}{$4.559(p=.336)$} \\
\hline Novice $(<1)$ & $93(18.0 \%)$ & $559(15.1 \%)$ & \\
\hline Advanced beginner (1) & $50(9.7 \%)$ & $329(8.9 \%)$ & \\
\hline Competent (2-3) & $113(21.9 \%)$ & $776(21.0 \%)$ & \\
\hline Proficient (4) & $28(5.4 \%)$ & $223(6.0 \%)$ & \\
\hline Expert $(5+)$ & $233(45.1 \%)$ & $1809(48.9 \%)$ & \\
\hline Primarily works day shift, 6:00 a.m.-6:00 p.m. ${ }^{*}$ & $388(75.0 \%)$ & $2789(75.5 \%)$ & $0.050(p=.823)$ \\
\hline
\end{tabular}

${ }^{\#}$ Some variables will not add to 4,213 due to missing data, ${ }^{\ddagger}$ Missing cases $(\mathrm{n}=32)$ were excluded from the calculation, ${ }^{*}$ Missing cases $(\mathrm{n}=2)$ were excluded from the calculation

\subsection{Hypothesis 1 - victimization while at work}

The percentage of mental health field respondents who experienced victimization while at work was significantly larger than the percentage of medical field employees $\left(15.5 \%\right.$ vs. $\left.7.7 \%, \chi^{2}=35.198, p<.001\right)$ (see Table 2$)$. Hypothesis 1 was therefore supported. When comparing specific types of violence, a significantly larger percentage of mental health field employees reported being grabbed, held, tripped, jumped, pushed, or spit upon $(p=.034)$ and being threatened with a weapon ( $p=.013$ ) compared to medical field employees. Mental health field employees also had a significantly larger percentage of respondents who had experienced two or more types of work-related victimization compared to medical field employees $(p=.001)$. Of particular note, the pattern of victimization between medical field and mental health field respondents was significantly different $\left(\chi^{2}=10.627, p=.014\right)$. Mental health field respondents were most likely to experience two or more types of assaults $(n=44,55 \%)$ followed by a single assault $(n=29,36.3 \%)$. Medical field respondents were most likely to experience a single assault $(n=155,55 \%)$ followed by two or more types of assaults $(n=$ $99,35.1 \%)$.

Table 2. Victimization in the workplace

\begin{tabular}{llll}
\hline & Mental health field & Medical field & $\mathbf{X}^{2}(\boldsymbol{p}$-value) \\
\hline $\begin{array}{l}\text { Respondents victimized } \\
\text { Of those victimized, the type of victimization: }\end{array}$ & $80(15.5 \%)$ & $283(7.7 \%)$ & $35.198(p<.001)$ \\
Abusive language or threats & $7(8.8 \%)$ & $28(9.9 \%)$ & $0.094(p=.760)$ \\
Grabbed, held, tripped, jumped, pushed, or spit upon & $60(75.0 \%)$ & $176(62.2 \%)$ & $4.499(p=.034)$ \\
Hit, slapped, or knocked down & $49(61.3 \%)$ & $153(54.1 \%)$ & $1.305(p=.253)$ \\
Hit with an object & $20(25.0 \%)$ & $54(19.1 \%)$ & $1.346(p=.246)$ \\
Threatened with a gun, knife, or other weapon & $12(15.0 \%)$ & $18(6.4 \%)$ & $6.140(p=.013)$ \\
Gun, knife, or other weapon used & $1(1.3 \%)$ & $2(0.7 \%)$ & $0.225(p=.636)$ \\
Sexual harassment, attempted rape, or rape & $0(0 \%)$ & $0(0 \%)$ & $3(1.1 \%)$ \\
Other physical attack & $0(0 \%)$ & $103(36.4 \%)$ & $0.855(p=.355)$ \\
Two or more types of victimization & $45(56.3 \%)$ & $10.181(p=.001)$ \\
\hline
\end{tabular}

(Table continued on page 176) 
Table 2. (continued.)

\begin{tabular}{llll}
\hline & Mental health field & Medical field & $\mathbf{X}^{2}(\boldsymbol{p}$-value) \\
\hline Pattern of victimization (mutually-exclusive groups) & & & \\
Abusive language or threats (no assault) only & $6(7.5 \%)$ & $24(8.5 \%)$ & $4(1.4 \%)$ \\
Abusive language or threats and assault only & $1(1.3 \%)$ & $10.627(p=.014)$ \\
Single assault type (no abusive language or threats) & $29(36.3 \%)$ & $155(55.0 \%)$ & \\
$2+$ assault types (no abusive language or threats) & $44(55.0 \%)$ & $99(35.1 \%)$ & \\
\hline
\end{tabular}

\subsection{Hypothesis 2 - worry about victimization}

The percentage of mental health field employees who worried about being attacked or threated with harm was significantly larger than the percentage of medical field employees who worried about being attacked or threatened (17.2\% vs. 9.5\%; $\chi^{2}=29.147, p<.001$ ). Hypothesis 2 was therefore supported. Mental health and medical field employees worried most about victimization by patients. However, the percentage of mental health field employees worrying about victimization by patients was significantly larger than the percentage of medical field employees $\left(89.9 \% v s .76 \%, \chi^{2}=\right.$ $8.196, p=.004)$. Additionally, a significantly higher percentage of mental health respondents felt that their workplace was not safe from crime compared to medical field respondents $\left(14.0 \% v s .10 .6 \%, \chi^{2}=4.171, p=.041\right)$.

\subsection{Hypothesis 3 - security measures in the workplace}

A significantly lower percentage of mental health field respondents had security measures in the workplace compared to medical field respondents $\left(60.9 \%\right.$ vs. $\left.76.9 \% ; \chi^{2}=62.048, p<.001\right)$ (see Table 3). Hypothesis 3 was therefore not supported. When evaluating the presence of the types of security measures present in the workplace, mental health field respondents had a significantly larger percentage compared to medical field respondents only for two types of security measures. Specifically, a significantly larger percentage of mental health field respondents worked in settings with locked entryways $(p<.001)$ and metal detectors $(p=.004)$ compared to medical field employees.

Table 3. Organizational protective measures to prevent and mitigate work-related victimization

\begin{tabular}{llll}
\hline & Mental health field & Medical field & $\mathbf{X}^{2}(p$-value) \\
\hline $\begin{array}{l}\text { Security measures present in the workplace } \\
\text { Of those with security measures present in the workplace, the }\end{array}$ & $315(60.9 \%)$ & $2844(76.9 \%)$ & $62.048(p<.001)$ \\
types of measures present were: & & & \\
Receptionist or guard who checks people in & $247(78.4 \%)$ & $2106(74.1 \%)$ & $2.839(p=.092)$ \\
Burglar alarm system & $155(49.2 \%)$ & $1270(44.7 \%)$ & $2.372(p=.124)$ \\
Surveillance camera & $113(35.9 \%)$ & $1279(45.0 \%)$ & $9.525(p=.002)$ \\
Pass or identification required to enter & $132(41.9 \%)$ & $1080(38.0 \%)$ & $1.852(p=.174)$ \\
Police or guards for protection & $91(28.9 \%)$ & $1180(41.5 \%)$ & $18.729(p<.001)$ \\
Locked entry or gate during working hours & $101(32.1 \%)$ & $640(22.5 \%)$ & $14.435(p<.001)$ \\
Metal detector & $19(6.0 \%)$ & $84(3.0 \%)$ & $8.519(p=.004)$ \\
X-ray inspection of bags/briefcases & $7(2.2 \%)$ & $30(1.1 \%)$ & $3.339(p=.068)$ \\
Guard dogs & $3(1.0 \%)$ & $41(1.4 \%)$ & $0.494(p=.482)$ \\
Of those with security measures in the workplace, those with & $223(70.8 \%)$ & $2153(75.7 \%)$ & $3.667(p=.056)$ \\
multiple $(2+)$ types of measures present & & & \\
Written rules or guidelines for workplace violence in the & & & \\
workplace & $398(77.0 \%)$ & $2596(70.2 \%)$ & $12.360(p=.002)$ \\
Yes & $95(18.4 \%)$ & $799(21.6 \%)$ \\
No & $24(4.6 \%)$ & $301(8.1 \%)$ & $2663(72.1 \%)$ \\
Don't know & $425(82.2 \%)$ & $23.893(p<.001)$ \\
Any education/information on workplace violence & &
\end{tabular}

(Table continued on page 177) 
Table 3. (Continued.)

\begin{tabular}{llll}
\hline & Mental health field & Medical field & $\mathbf{X}^{\mathbf{2}}(\boldsymbol{p}$-value) \\
\hline $\begin{array}{l}\text { Of those with any education/information on workplace } \\
\text { violence, the type of education/information: }\end{array}$ & & & \\
General brochure on workplace violence & $259(60.9 \%)$ & $1698(63.8 \%)$ & $1.257(p=.262)$ \\
Memo or policy reporting workplace violence & $335(78.8 \%)$ & $1953(73.3 \%)$ & $5.745(p=.017)$ \\
Memo or policy reporting security measures & $242(56.9 \%)$ & $1669(62.7 \%)$ & $5.106(p=.024)$ \\
Other written materials & $38(8.9 \%)$ & $202(7.6 \%)$ & $0.940(p=.332)$ \\
Brief seminar & $208(48.9 \%)$ & $1094(41.1 \%)$ & $9.284(p=.002)$ \\
Full workplace violence seminar & $180(42.4 \%)$ & $782(29.4 \%)$ & $28.824(p<.001)$ \\
Hands-on training in conflict resolution & $220(51.8 \%)$ & $718(27.0 \%)$ & $106.608(p<.001)$ \\
Hands-on training in restraint or management & $201(47.3 \%)$ & $694(26.1 \%)$ & $80.280(p<.001)$ \\
Other type of training & $34(8.0 \%)$ & $121(4.5 \%)$ & $9.183(p=.002)$ \\
Of those receiving any education/information on workplace & $362(85.2 \%)$ & $2146(80.6 \%)$ & $5.063(p=.024)$ \\
violence, those with multiple $(2+)$ types of education/information & & & \\
\hline
\end{tabular}

\subsection{Hypothesis 4 - written rules or guidelines for workplace violence}

The percentage of mental health field respondents (77\%) reporting their knowledge of rules or guidelines addressing workplace violence was larger than the percentage of medical field respondents $(70.2 \%)$ reporting the same. The distribution of percentages between mental health and medical field respondents was significant $\left(\chi^{2}=12.360, p=.002\right)$; hence Hypothesis 4 was supported (see Table 3).

\subsection{Hypothesis 5 - education/ information about workplace violence}

A significantly larger percentage of mental health field respondents received education/information on workplace violence compared to medical field respondents $\left(82.2 \%\right.$ vs. $\left.72.1 \%, \chi^{2}=23.893, p<.001\right)$ (see Table 3). Hypothesis 5 was therefore supported. In addition, among those respondents who received education/information on workplace violence, mental health field respondents were significantly more likely than medical field respondents to report receiving two or more types of education/information on workplace violence $\left(85.2 \%\right.$ vs. $\left.80.6 \%, \chi^{2}=5.063, p=.024\right)$.

\subsection{Hypothesis 6 - use of personal protection}

A larger percentage of mental health field respondents $(n=29,5.6 \%)$ reported using personal protective measures to reduce their risk of being victimized while at work compared to medical field respondents $(\mathrm{n}=174,4.7 \%)$. The comparison of the use of personal protective measures between the fields was not significant indicating that Hypothesis 6 was not supported $\left(\chi^{2}=0.804, p=.370\right)$. The type of personal protection most commonly used by respondents in both fields was mace or pepper spray; however, the comparison between fields was not significant $(n=13,44.8 \%$ vs. $n=103$, $59.2 \% ; p=.148)$. Personal protective devices less commonly used by mental health and medical field respondents were a personal alarm device $(n=13,44.8 \%$ vs. $n=46,26.4 \%)$, firearm $(n=0,0 \% v s . n=10,5.7 \%)$, knife $(n=2,6.9 \%$ vs. $n=19$, $10.9 \%)$, and communication device or panic button ( $\mathrm{n}=2,6.9 \%$ vs. $\mathrm{n}=0,0 \%)$.

\section{Discussion}

This study fills a gap in the work-related victimization research by testing and reporting six hypotheses for the comparison of work-related victimization in and protective measures used by a large U.S. sample of medical and mental health field employees. The evidence supported four of the six hypotheses: a significantly higher percentage of mental health field respondents compared to medical field respondents were victimized while at work, worried about victimization, had knowledge of rules or guidelines addressing workplace violence, and received education/information on workplace violence. The results of the study hypotheses are discussed in the following paragraphs. 
A larger percentage of mental health field respondents experienced victimization while at work compared to medical field respondents $(p<.001)$. The mental health field is commonly cited along with a few medical field specialty areas, such as the emergency department, as having the highest rate of victimization ${ }^{[16]}$. Bearing in mind the NCVS sample was drawn using a stratified, multistage cluster design, the WRS sample did not target higher risk areas such as the emergency department. Although nurses tend to have a high degree of victimization, nurses only comprised $28.8 \%$ of the medical field employees. Therefore, the pool of study respondents was most likely drawn from employees with documented lower rates of work-related victimization such as those working in medical/surgical and pediatric hospital units.

Significantly $(p=.004)$ more mental health field employees worried about victimization by patients compared to medical field employees. This finding contrasted Blando, O'Hagan, Casteel, Nocera, and Peek-Asa who found that psychiatric nurses were significantly less likely to be concerned about work-related victimization than emergency nurses ${ }^{[25]}$. One plausible explanation for this difference between the two findings may be because the current study included all employees within the two fields and was not exclusive to nurses who ordinarily have the most direct contact with patients.

Mental health field employees may have felt more vulnerable than medical field employees given the significantly larger percentage of mental health field employees who perceived their workplaces were unsafe or very unsafe. This perception of the lack of workplace safety may heighten the awareness of one's risk for victimization and feeling unsafe. A perceived lack of personal safety may be an antecedent to worrying about victimization. Blando et al. found that emergency nurses felt unsafe significantly more often than mental health nurses $(p<.001)^{[25]}$. They argued that this perception of safety was likely related to emergency nurses working in open, unsecured environments and providing care to patients with whom they did not have a relationship ${ }^{[25]}$.

The significantly lower percentage of mental health field employees with security measures present in the workplace was surprising and contradicted Casteel et al.'s finding: California emergency departments were less likely to have security measures compared to California psychiatric units ${ }^{[16]}$. This finding may be due in part to nearly $20 \%$ of the mental health field employees traveling to multiple locations during their workday compared to $11 \%$ of medical field employees, and possibly not considering the security measures of the places they visited when answering this question. The higher percentage of medical field employees with security measures also may be due to respondents working throughout the United States (not just California) and in hospital settings that are more likely to have surveillance cameras protecting certain higher risk areas such as the emergency department, intensive care unit, and outpatient pharmacy.

A logical conclusion for the implementation of workplace violence prevention programs is that written rules or guidelines would address the presence and use of security measures. Therefore, it would be expected that the percentage of employees reporting both the presence of written rules or guidelines and security measures would be nearly equal. However, this was not the case in the WRS sample, but is consistent with Peek-Asa et al. who reported a mismatch in the percentage of psychiatric units and facilities that had both policies and security measures present in the workplace ${ }^{[24]}$. While $77 \%$ of the WRS mental health field respondents worked for employers with written rules or guidelines for workplace violence, only $60.9 \%$ reported the presence of security measures. The opposite was true for medical field respondents: a larger percentage of employees reported the presence of security measures (76.9\%) compared to written rules or guidelines for workplace violence (70.2\%). Casteel et al. explained that psychiatric units were more likely to have workplace violence policies in place compared to emergency departments ${ }^{[16]}$. Our findings possibly could reflect a lack of employer's awareness of the risk for workplace violence in medical field work settings.

Less than 5\% $(\mathrm{n}=203)$ of the respondents in our WRS sample used personal protective measures in the workplace. This result was somewhat surprising given $10.4 \%(\mathrm{n}=439)$ of the total respondents worried about victimization and $8.6 \%(\mathrm{n}=$ 363) were previously victimized. Respondents may not have been aware of the devices that could be used for their personal protection, such as a personal alarm device. Healthcare employers may not provide communication devices or panic buttons in the workplace and likely prohibit employees from carrying personal weapons such as firearms and knives 
while on duty or company property. If, however, personal weapons are carried particularly by employees traveling to multiple locations for work, it is imperative that they be properly trained in the safe use of the weapon and ensure patients or visitors do not acquire the weapon to use against the employee. Education also is essential for both mental health and medical field employees as to the ease of use and cost effectiveness of devices like personal alarms that can be used for personal protection. Simulated training sessions where employees practice using their personal protective devices may further increase the use of personal protective devices while simultaneously potentially reducing the rate of victimization. Although all $(n=143)$ psychiatric nurses and $86 \%(n=268)$ of the emergency nurses in Blando et al.'s study received violence prevention training, the specific training for personal protective devices was not known ${ }^{[25]}$.

\subsection{Limitations}

There were three limitations for this study. First, the data were collected during 2002 and may not be reflective of contemporary practices. However, given the focus of current research with specialty practice areas or single hospital settings, this study contributes to the science of work-related victimization in healthcare. Second, respondents were recruited from a very large probabilistic sample of households in the U.S. and may not be representative of mental health and medical field employees not invited to complete the WRS survey. Third, a comparison of the respondents' demographic characteristics could not be compared to the overall healthcare employee population, because demographic parameters for mental health and medical field employees were not available.

\subsection{I mplications for hospital administrators}

Security measures have the potential to increase environmental safety and improve employee perceptions of personal safety while at work ${ }^{[25]}$. Security measures that should be considered by hospital administrators if not already in place are a quick response from security, adequate security equipment, and regular updates on work-related victimization ${ }^{[25]}$. Hospital administrators facilitating a strong collaborative relationship between security officers and healthcare employees is an essential step towards improving safety in the workplace and perceptions of safety by employees ${ }^{[18]}$.

Hospital administrators can target periodic communications to employees to further increase the percentage of employees knowledgeable about written rules, guidelines, and information on workplace violence initiatives. For example, a monthly newsletter could communicate general announcements as well as include a Safety Spotlight Feature describing how security officers are used in the organization to protect employees. During a following month, the newsletter can inform employees where they can retrieve written rules or guidelines, how they were developed, and how frequently they are reviewed and updated. Ultimately, public policy may need to be adopted by the Occupational Safety and Health Administration mandating a minimum standard for healthcare organizations to achieve for protecting employees against work-related victimization.

Passive learning strategies such as the distribution of brochures, memos, and policies were the most common types of education/information on workplace violence in the WRS sample. Unfortunately, passive learning has less chance of being recalled by employees when the information is needed. Active learning strategies increase the chance that learning will be retained long term by employees when the information is needed ${ }^{[26]}$. Gillespie, Farra, and Gates reported the significant increase in knowledge achieved after emergency department employees completed highly interactive discussions on how to prevent and manage simulated events of work-related victimization ${ }^{[27]}$. Hospital administrators in collaboration with risk managers have access to case reports of real incidents of work-related victimization that can be used as the foundation for similar educational programs taught using active learning strategies. Hospital administrators also can charge interprofessional teams to design and implement educational programs using active learning strategies.

\section{Conclusion}

Work-related victimization was a profound problem for this national sample of mental health and medical field employees, especially so for those employees working in the mental health field. Employers need to increase the 
effectiveness of their workplace violence prevention programs so that employees recognize and understand the written rules or guidelines and security measures in place to prevent work-related victimization. Hospital administrators also need to collaborate with employees, hospital managers, and risk managers for the adoption and use of personal protective measures in the workplace. As employees' knowledge of and participation in workplace violence prevention programs increase, employees may begin to feel more safe in the workplace and less worried and fearful about future work-related victimization. Future research needs to examine the effectiveness of education, presence of security measures, and use of personal protective measures and the effectiveness of these measures for reducing rates of employee work-related victimization.

\section{Conflict of interests}

The authors declare they have no conflict of interests.

\section{Acknowledgement}

Support for this publication was provided in part by a grant from the Robert Wood Johnson Foundation. The authors wish to dedicate this article to the memory of E. Lynn Jenkins, PhD, Division of Violence Prevention, National Center for Injury Prevention and Control. Lynn was instrumental in developing the Workplace Risk Supplement (WRS) to the NCVS; while working at NIOSH, she was devoted to understanding workplace violence and its prevention. Bonnie thanks her for continuously sparking her interest in workplace violence and selecting her to collaborate on the development and analysis of the WRS.

\section{References}

[1] Bureau of Labor Statistics. Survey of workplace violence prevention, 2005. Washington (DC): Author; 2006 Oct. Bureau of Labor Statistics News Report No.: 06-1860.

[2] Bureau of Labor Statistics. 2000 standard occupational classification (SOC) user guide. Washington (DC): Author; 2011 Mar. Available from: http://www.bls.gov/soc/socguide.htm

[3] University of Iowa Injury Prevention Research Center. Workplace violence: A report to the nation. Iowa City (IO): Author; 2001 Feb. Available from: http://www.public-health.uiowa.edu/iprc/resources/workplace-violence-report.pdf

[4] Bureau of Labor Statistics. Nonfatal occupational injuries and illnesses requiring days away from work, 2011. Washington (DC): Author; 2012 Nov. Bureau of Labor Statistics News Release Report No.: 12-2204.

[5] Jenkins EL, Fisher BS, Hartley D. Safe and secure at work? Findings from the 2002 Workplace Risk Supplement. WORK: J Prevention, Assessment Rehabilitation. 2012; 42: 57-66.

[6] Kitaneh M, Hamdan M. Workplace violence against physicians and nurses in Palestinian public hospitals: a cross-sectional study. BMC Health Services Res. 2012; 12: 469. Available from: http://www.biomedcentral.com/1472-6963/12/469. PMid: 23256893. http://dx.doi.org/10.1186/1472-6963-12-469

[7] Gacki-Smith J, Juarez AM, Boyett L, Homeyer C, Robinson L, MacLean SL. Violence against nurses working in US emergency departments. J Nurs Admin. 2009; 39: 340-349. PMid: 19641432. http://dx.doi.org/10.1097/NNA.0b013e3181ae97db

[8] Kowalenko T, Gates D, Gillespie GL, Succop P, Mentzel TK. Prospective study of violence against ED workers. Am J Emerg Med. 2013; 31(1): 197-205. http://dx.doi.org/10.1016/j.ajem.2012.07.010

[9] Opie T, Lenthall S, Dollard M, Wakerman J, MacLeod M, Knight S, et al. Trends in workplace violence in the remote area nursing workforce. Australian J Advanced Nurs. 2010; 27(4): 18-23.

[10] Harris B, Leather P. Levels and consequences of exposure to service user violence: Evidence from a sample of UK social care staff. Brit J Social Work. 2012; 42: 851-869. http://dx.doi.org/10.1093/bjsw/bcr128

[11] Hegney D, Tuckett A, Parker D, Eley RM. Workplace violence: Differences in perceptions of nursing work between those exposed and those not exposed: A cross-sector analysis. Int J Nurs Pract. 2010; 16: 188-202.

http://dx.doi.org/10.1111/j.1440-172X.2010.01829.x

[12] Chen W, Huang C, Hwang J, Chen C, The relationship of health-related quality of life to workplace physical violence against nurses by psychiatric patients. Quality Life Res. 2010; 19: 1155-1161. http://dx.doi.org/10.1007/s11136-010-9679-4

[13] Fitzgerald D, Reid A. Frequency and consequences of violence in community pharmacies in Ireland. Occupational Med. 2012; 62: 632-637. http://dx.doi.org/10.1093/occmed/kqs154 
[14] Hutchings D, Lundrigan E, Mathews M, Lynch A, Goosney J. Keeping community health care workers safe. Home Health Care Management Pract. 2011; 23: 27-35. http://dx.doi.org/10.1177/1084822309360383

[15] Blando JD, McGreevy K, O’Hagan E, Worthington K, Valiante D, Nocera M, et al. Emergency department security programs, community crime, and employee assaults. J Emerg Med. 2012; 42(3): 329-338. http://dx.doi.org/10.1016/j.jemermed.2008.06.026

[16] Casteel C, Peek-Asa C, Nocera M, Smith JB, Blando J, Goldmacher S, et al. Hospital employee assault rates before and after enactment of the California Hospital Safety and Security Act. Ann Epidemiology. 2009; 19(2): 125-133. http://dx.doi.org/10.1016/j.annepidem.2008.10.009

[17] McPhaul KM, London M, Murrett K, Flannery K, Rosen J, Lipscomb J. Environmental evaluation for workplace violence in healthcare and social services. J Safety Res. 2008; 39: 237-250. http://dx.doi.org/10.1016/j.jsr.2008.02.028

[18] Gillespie GL, Gates DM, Miller M, Howard PK. Emergency department workers' perceptions of security officers' effectiveness during violent events. WORK: J Prevention, Assessment, Rehabilitation. 2012; 42(1): 21-27. http://dx.doi.org/10.3233/WOR-2012-132

[19] Inter-university Consortium for Political and Social Research. National Crime Victimization Survey, 1992-2002 (Report No.: 3691). Ann Arbor, MI: Author; 2004 Sep.

[20] Maxfield MG. Household composition, routine activity, and victimization: A comparative analysis. J Quantitative Criminology. 1987; 3(4): 301-320. http://dx.doi.org/10.1007/BF01066833

[21] Benner P. From novice to expert: Excellence and power in clinical nursing practice. Menlo Park, CA: Addison-Wesley. 1984.

[22] Shiao JS, Tseng Y, Hsieh Y, Hou J, Cheng Y, Guo YL. Assaults against nurses of general and psychiatric hospitals in Taiwan. Int Archives Occupational Environmental Health. 2010; 83: 823-832. http://dx.doi.org/10.1007/s00420-009-0501-y

[23] Gillespie GL, Gates DM, Berry P. Stressful incidents of physical violence against emergency nurses. The Online J Issues Nurs. 2013; 18(1): 2. http://dx.doi.org/10.3912/OJIN.Vol18No01Man02

[24] Peek-Asa C, Casteel C, Allareddy V, Nocera M, Goldmacher S, O’Hagan E, et al. Workplace violence prevention programs in psychiatric units and facilities. Archives Psychiatric Nurs. 2009; 23(2): 166-176. http://dx.doi.org/10.1016/j.apnu.2008.05.008

[25] Blando JD, O'Hagan E, Casteel C, Nocera M, Peek-Asa C. Impact of hospital security programmes and workplace aggression on nurse perceptions of safety. J Nurs Management. 2013; 21: 491-498. http://dx.doi.org/10.1111/j.1365-2834.2012.01416.x

[26] Gillespie GL, Farra SL, Gates DM, Howard PK, Atkinson KL. The qualitative learning experience of healthcare workers completing a hybrid workplace violence educational program. J Nurs Education Pract. 2013; 3(11): 54-64. http://dx.doi.org/10.5430/jnep.v3n11p54

[27] Gillespie GL, Farra SL, Gates DM. Workplace violence knowledge retention: A repeated measures study. Nurs Education Pract. 2014. http://dx.doi.org/10.1016/j.nepr.2014.04.003 